\title{
Endogenous Hydrogen Sulfide Ameliorates NOX4 Induced Oxidative Stress in LPS- Stimulated Macrophages and Mice
}

\author{
Xi-Ling Wang ${ }^{a, b}$ Li-Long Pan ${ }^{a}$ Fen Long ${ }^{a}$ Wei-Jun Wu ${ }^{a}$ Di Yan ${ }^{a}$ Peng $X^{a}$ \\ Si-Yu Liu ${ }^{a}$ Ming Qina Wan-Wan Jia ${ }^{a}$ Xin-Hua Liua Yi Zhun Zhua,b \\ aShanghai Key Laboratory of Bioactive Small Molecules, Department of Pharmacology, School of

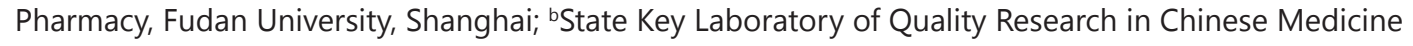 \\ and School of Pharmacy, Macau University of Science and Technology, Macau, China
}

\section{Key Words}

Nadph oxidase $4 \cdot$ Hydrogen sulfide $\cdot$ Cystathionine- $\gamma$-lyase $\cdot$ Inflammation $\bullet$ Sepsis

\begin{abstract}
Background/Aims: Sepsis is a severe and complicated syndrome that is characterized by dysregulation of host inflammatory responses and organ failure. Cystathionine- $\gamma$-lyase (CSE)/ hydrogen sulfide $\left(\mathrm{H}_{2} \mathrm{~S}\right)$ has potential anti-inflammatory activities in a variety of inflammatory diseases. NADPH oxidase 4 (Nox4), a member of the NADPH oxidases, is the major source of reactive oxygen species (ROS) and its expression is increased in sepsis, but its function in CSE-mediated anti-inflammatory activities remains unknown. Methods: Macrophages were either transfected with CSE, Nox4 siRNA or transduced with lentiviral vector encoding CSE or Nox4, and then stimulated with lipopolysaccharide (LPS). The expression of inflammatory mediators and signaling pathway activation were measured by quantitative PCR (qPCR), ELISA, and immunoblotting. LPS-induced shock severity in WT, Nox4 knockdown and CSE knockout $\left(\mathrm{CSE}^{--}\right)$mice was assessed. Results: Here we showed that CSE and Nox4 were upregulated in macrophage and mouse in response to LPS. After LPS stimulation, the inflammatory responses were significantly ameliorated by lentiviral Nox4 shRNA knockdown, but were exacerbated by lentiviral overexpressing Nox4. Furthermore, Nox4 mediated inflammation through PI3K/Akt and p-p38 mitogen-activated protein kinase signal pathway. Notably, CSE knockout served to amplify the inflammatory cascade by increasing Nox4-ROS signaling activation in septic mice and macrophage. Similarly, the enhanced production of inflammatory mediators by macrophages was reduced by CSE overexpression. Conclusion: Thus, we demonstrated that $\mathrm{CSE} / \mathrm{H}_{2} \mathrm{~S}$ attenuated LPS-induced sepsis against oxidative stress and inflammation damage probably largely through mediated Nox4 pathway.

(C) 2018 The Author(s)

Published by S. Karger AG, Basel
\end{abstract}

\section{Introduction}

Sepsis is rapidly developing conditions with a poor prognosis and high morbidity and mortality [1]. Sepsis and septic shock caused by the microbial invasion of normally sterile

Prof. YiZhun Zu and

Assoc. Prof. Xin-Hua Liu 
body parts triggers an uncontrolled systemic inflammatory response and subsequent organ failure [2]. However, beyond antibiotic therapy, therapeutic drugs against septic disease remain elusive. The endotoxin lipopolysaccharide (LPS) from Gram-negative bacteria is known to be potent stimuli of inflammatory responses via toll-like receptor 4 (TLR4), which plays critical roles in the development of sepsis in response to exogenous pathogens. Although past efforts have identified multiple critical regulators to modulate TLR-signaling in response to endotoxin shock, the molecular mechanisms that regulate septic shock are still poorly understood [2].

Sepsis and septic shock are associated with increased production of reactive oxygen species (ROS). ROS function as signaling molecules to activate multiple signal cascades to modulate inflammatory responses $[3,4]$. The NADPH oxidase (Nox) family, as a major source of ROS [3], is thought to be responsible for inflammation, injury, and possibly tissue repair in pathological process of septic shock [5]. Nox family has several isoforms, in which Nox2 and Nox4 are the main isoform that can be induced and appear important in the etiology of various diseases, including sepsis [6,7]. Thus, regulating NADPH oxidase-mediated signaling may effectively modulate inflammatory responses and improve survival in sepsis, but so far, the underlying mechanisms of isoform Nox4 during the inflammatory phase of sepsis are largely unknown.

Hydrogen sulfide $\left(\mathrm{H}_{2} \mathrm{~S}\right)$, the third endogenous gasotransmitter, is capable of regulating various endogenous signaling pathways $[8,9]$. Endogenous $\mathrm{H}_{2} \mathrm{~S}$ production has attributed to three key enzymes cystathionine $\gamma$-lyase (CSE), cystathionine $\beta$-synthetase, and 3-mercaptopyruvate sulfurtransferase [8]. The expression of $\mathrm{H}_{2} \mathrm{~S}$-producing enzymes is tissue specific. Cystathionine $\beta$-synthetase and 3-mercaptopyruvate sulfurtransferase are most abundantly expressed in central nervous system, whereas the CSE mainly occurs in liver, kidney, and blood vessels [10]. A number of studies have demonstrated that the CSE/ $\mathrm{H}_{2} \mathrm{~S}$ pathway may be involved in a multitude of pathophysiologic processes of various disease, such as cardiovascular diseases [8,11,12], neurodegenerative diseases [13], and so on. The role exerted by $\mathrm{H}_{2} \mathrm{~S}$ in inflammation remains controversial because it is reported to have both inflammatory and anti-inflammatory activities. In animal models of sepsis, both the pharmacological inhibition of $\mathrm{H}_{2} \mathrm{~S}$ synthesis [14] as well as $\mathrm{H}_{2} \mathrm{~S}$ donor administration [15] were shown to alleviate organ injury.

Here, for the first time, we demonstrated that CSE/ $\mathrm{H}_{2} \mathrm{~S}$ attenuated LPS-induced sepsis against oxidative stress and inflammation damage probably largely through mediated Nox4 pathway.

\section{Materials and Methods}

\section{Mice}

Eight-week-old male C57BL/6J mice were purchased from Sippr-BK Experimental Animal Center, Shanghai, China. The CSE knockout (CSE $/$ ) C57BL/6J mice were a kind gift from Shanghai Research Center of Model Organisms (Shanghai, China), and eight-week-old male $\mathrm{CSE}^{-/-}$used in this study. All animals received humane care in compliance with the principles of laboratory animal care formulated by Fudan University for medical research and the Guide for the Care and Use of Laboratory Animals.

\section{Reagents and antibodies}

Dulbecco's modified Eagle's medium (DMEM) medium and fetal bovine serum (FBS) was purchased from GIBCO-BRL (USA). N-acetyl- $L$-cysteine (NAC), diphenylene iodonium (DPI), NaHS, and LPS (E. coli serotype 055:B5) were obtained from Sigma (St. Louis, MO). Carboxy-PTIO potassium salt (c-PTIO), catalase (CAT), and superoxide dismutase (SOD) were purchased from Beyotime (Beyotime Biotechnology, Jiangsu, China). LY294002 and SB203580 were obtained from Calbiochem (Dermstadt, Germany). Antibodies against $\beta$-Actin, CSE, iNOS, COX-2, Nox4 were obtained from Santa Cruz Biotechnology (Santa Cruz, CA). Total- and phosphor (p) -p38 (Thr ${ }^{180}$ and Tyr $^{182}$ ), total- and p-extracellular signal-regulated kinase 1/2 (ERK) (Thr ${ }^{202} /$ Tyr $^{204}$ ), total- and p-Akt (Ser ${ }^{473}$ ), and p-glycogen synthase kinase-3 $\beta$ (GSK3 $\beta$ ) $\left(\right.$ Ser $\left.^{9}\right)$ were purchased from Cell Signaling Technology (Danvers, MA).

\section{KARGER}




\section{Cellular Physiology Cell Physiol Biochem 2018;47:458-474 \begin{tabular}{l|l} 
DOI: 10.1159/000489980 & Ond Biochemistry \\
Published online: May 24, 2018 & $\begin{array}{l}\text { 2018 The Author(s). Published by S. Karger AG, Basel } \\
\text { www.karger.com/cpb }\end{array}$
\end{tabular} \\ Wang et al.: $\mathrm{H}_{2} \mathrm{~S}$ Modulates Inflammation Through Nox4 Activation}

Cell culture and treatment

The murine macrophage cell line, RAW264.7 cells (American Type Culture Collection), were cultured and propagated in DMEM medium supplemented with $10 \% \mathrm{FBS}, 100 \mathrm{U} / \mathrm{ml}$ penicillin, and $100 \mu \mathrm{g} / \mathrm{ml}$ streptomycin (GIBCO) at $37^{\circ} \mathrm{C}$ in humidified atmosphere of $5 \% \mathrm{CO}_{2}$.

\section{SiRNA interference}

Mouse RAW264.7 macrophages were transfected with mouse CSE-specific siRNA (sc-142618) or control siRNA (sc-36869) (both from Santa Cruz Biotechnology, Santa Cruz, CA) using Lipofectamine RNAiMAX (Life Technologies, Shanghai, China) according to the manufacturer's instructions. Briefly, individual siRNAs (at 25 to $50 \mathrm{nM}$ ), Lipofectamine RNAiMAX, and Opti-MEM were mixed and incubated at room temperature for $5 \mathrm{~min}$. siRNA-lipofectamine RNAiMAX complexes were added to cells for $24 \mathrm{~h}$ and the medium was replaced by fresh serum DMEM medium after transfection. Experiments were performed $72 \mathrm{~h}$ after transfection. Knockdown of CSE was assessed by Western blot.

\section{Intracellular ROS and $\mathrm{H}_{2} \mathrm{~S}$ measurement}

The intracellular ROS production was measured using a $\mathrm{H}_{2}$ DCF-DA probe as our previously described [16]. At $70 \%$ to $80 \%$ confluence, cells were stimulated with LPS $(1 \mu \mathrm{g} / \mathrm{ml})$ for $4 \mathrm{~h}$ and washed, then incubated with $\mathrm{H}_{2}$ DCF-DA $(20 \mu \mathrm{M})$ in medium $\left(37^{\circ} \mathrm{C}, 45 \mathrm{~min}\right)$. After washing twice more, cells were exposed to experimental conditions as described below. Fluorescence signals were analyzed at excitation $485 \mathrm{~nm} /$ emission $535 \mathrm{~nm}$ (M1000, TECAN, Switzerland). Data were presented as fold change versus control after background subtraction.

The $\mathrm{H}_{2} \mathrm{~S}$ levels in the serum from mice and RAW264.7 cells were measured as previously described $[17,18]$. In brief, $30 \mu \mathrm{L}$ serum or supernatant of macrophages was mixed with $10 \mu \mathrm{L}$ Tris- $\mathrm{HCl}(200 \mathrm{mM}, \mathrm{pH}$ 8.5) and $70 \mu \mathrm{L}$ monobromobimane solution $(3.5 \mathrm{mM})$ at room temperature for $1 \mathrm{~h}$. The reaction product sulfide dibimane (SDB) was analyzed with mass spectrometry. The $\mathrm{H}_{2} \mathrm{~S}$ concentrations were determined using a curve created with sodium sulfide $(0-40 \mu \mathrm{mol} / \mathrm{L})$ standards and results were presented as fold change versus control.

\section{Inflammatory cytokines detection}

Cell culture supernatants and mice sera were analyzed for inflammatory cytokine levels using the commercial ELISA set for the detection of IL-6, TNF- $\alpha$, IL-1 $\beta$ (from BD Pharmingen), or PGE 2 (Abcam). All assays were performed as recommended by the manufacturers. Optical densities were read on a microplate reader at $450 \mathrm{~nm}$. Results are presented with $\mathrm{pg} / \mathrm{ml}$.

\section{NADPH oxidase activity measurement}

NADPH oxidase activity was assessed as described earlier [16]. Briefly, whole cell membranes or lungs tissue extracts were prepared, Nox activity was measured using a commercially available kit (Genmed Scientifics, Shanghai, China) according to the manufacturer's instructions. The dynamic tracings of NADPHdependent activity were recorded every minute for $15 \mathrm{~min}$ with a luminometer (VarioSkan Flash; Thermo Scientific, Waltham, MA, USA). NADPH oxidase activity was expressed as relative luminescence units (RLU), corrected for protein concentration. The differences in NADPH oxidase activity were quantified as the percentage change from the respective control values.

\section{Measurement of total nitrite level and NO production}

RAW 246.7 cells were plated in 12-well cell culture plates. After indicated treatment, cells were stimulated with or without LPS $(1 \mu \mathrm{g} / \mathrm{ml})$ for $12 \mathrm{~h}$, total nitrite was measured using the nitrite detection Kit (Beyotime Biotechnology, Jiangsu, China) and according to the manufacturer's instructions. In brief, $50 \mu \mathrm{L}$ each of both the cell-free supernatant and $2 \times$ Griess reagent were mixed for a Griess reagent final concentration at room temperature, and the absorbance was measured at $540 \mathrm{~nm}$ and calculated using a standard curve obtained by series concentrations of sodium nitrite.

Treated RAW264.7 were incubated with $10 \mu \mathrm{M}$ 4-amino-5-methylamino-2', $7^{\prime}$-difluorofluorescein (DAF-FM DA; Molecular Probes) at $37^{\circ} \mathrm{C}$ for $45 \mathrm{~min}$. The cells were rinsed and were harvested in PBS. Subsequently, cells were transferred to a black 96-well microplate (Nunc, Thermo Scientific) and then the fluorescence intensity was measured at an excitation and emission wavelength of $495 \mathrm{~nm}$ and $515 \mathrm{~nm}$, 


\section{Cellular Physiology Cell Physiol Biochem 2018;47:458-474 \begin{tabular}{l|l} 
DOI: 10.1159/000489980 & O 2018 The Author(s). Published by S. Karger AG, Basel \\
www.karger.com/cpb
\end{tabular} \\ Wang et al.: $\mathrm{H}_{2} \mathrm{~S}$ Modulates Inflammation Through Nox4 Activation}

respectively, using a fluorescence spectrophotometer (M1000, TECAN). The differences in intracellular NO level were calculated as relative fluorescence intensity and were quantified as the percentage change from the respective control values as previously described [19].

\section{Lentivirus production and infection}

All of the lentiviruses were generated in HEK293T after transient transfection with lipofectamine 2000 (ThermoFisher Scientific, Shanghai, China) and plasmids. Lentivirus-containing medium was collected every $24 \mathrm{~h}$ for 3 days, and cellular debris was cleared by low-speed centrifugation and passage through a $0.45-\mu \mathrm{m}$ filter (Millipore, Billerica, USA). The collected medium was concentrated with the PEG-it ${ }^{\mathrm{TM}}$ virus precipitation solution (SBI, Mountain View, USA), and pellets containing viral particles were re-suspended with DMEM. The lentivirus was added to the culture medium with the plolybrene ( $8 \mu \mathrm{g} / \mathrm{mL}$, Sigma-Aldrich). The infection efficiency of lentivirus was verified under the fluorescence microscope.

\section{Experimental animals and lentiviral transduction}

Mice were injected with either saline or lentivirus via their tail veins. In total, 5 injections were administered, on alternate days, over a period of 9 days. For each injection, $0.2 \mathrm{~mL}$ of the concentrated viral suspension with a titer of $1 \times 10^{8} \mathrm{IU} / \mathrm{mL}$ was administered. Mice received an intraperitoneal (i.p) injection of LPS $(30 \mathrm{mg} / \mathrm{kg}) 1$ day after the last administration of lentivirus. $24 \mathrm{~h}$ after the LPS administration, the mice were sacrificed for measuring inflammatory mediators. The survival of mice subjected to LPS was monitored for 7 days. Control mice were maintained on a standard rodent diet and injected with the same volume of normal saline.

\section{Lysate preparation and western blot analysis}

Total lysis of the cells or tissues was carried out with RIPA buffers as described before [20]. The protein concentration was determined by protein assay kit (Thermo scientific). Western blot was performed as previously described [21]. In brief, equal amounts of protein were separated in SDS-polyacrylamide gels and transferred to a nitrocellulose membrane (GE healthcare). The membrane was probed with primary antibody overnight at $4^{\circ} \mathrm{C}$. Immunecomplexes were detected by enhanced chemiluminescence (Millipore, Billerica, USA) with horseradish peroxidase conjugated anti-mouse or anti-rabbit IgG as the secondary antibody (ThermoFisher Scientific, Shanghai, China). Signal intensity was quantified using the software Alpha Imager (Alpha Innotech Corp, San Leandro, CA). The results were expressed as fold changes by normalizing the data to the control values.

\section{Morphometric analysis and immunofluorescence staining}

At $24 \mathrm{~h}$ post-LPS injection, the mice were anesthetized by sodium pentobarbital. The lungs were harvested, fixed with $4 \%$ paraformaldehyde and paraffin-embedded. For morphometric analysis, the sections were stained with haematoxylin and eosin (H\&E) after deparaffinization and rehydration. For immunofluorescence staining, the lung sections were blocked in PBS with $10 \%$ goat serum for $1 \mathrm{~h}$ and incubated overnight with primary antibodies at $4^{\circ} \mathrm{C}$. Appropriate secondary antibodies were added and incubated for $1 \mathrm{~h}$ at $37^{\circ} \mathrm{C}$. The nuclei were stained with DAPI. The images were captured by using a fluorescence microscope.

\section{Statistical analysis}

Results are expressed as mean \pm standard error of the mean (SEM). All data analysis was performed with the use of GraphPad Prism 5 software. Differences between mean values of multiple groups were analyzed by one-way analysis of variance with Tukey's test for post hoc comparisons. Statistical significance was considered at $P<0.05$.

\section{Results}

Nox4 is involved in LPS-induced inflammatory response in macrophages

We measured the effects of bacterial product LPS on the expression of Nox4 in mouse macrophages. We found that Nox4 was strongly induced by LPS in a time dependent manner 
(Fig. 1A). Meanwhile, the inflammatory mediators (NO or total nitrite, $\mathrm{PGE}_{2}$, iNOS, and COX2 ) and inflammatory cytokines (IL-6, TNF- $\alpha$, IL-1 $\beta$ ) also were analyzed after LPS stimulation. Consistent with the Nox4 expression, the production of inflammatory mediators $\mathrm{PEG}_{2}$ (Fig. 1B), NO or total nitrite (Fig. 1C) were markedly increased. The expression of iNOS and COX-2 (Fig. 1D) and release of inflammatory cytokines (IL-6, TNF- $\alpha$, IL-1 $\beta$ ) (Fig. 1E) were timedependently upregulated after LPS stimulation.

\section{Nox4 promotes LPS-induced inflammatory mediators}

NADPH oxidase-derived ROS production mediates LPS-induced macrophages activation [19]. Therefore, the intracellular ROS generation and NADPH oxidase activity were analyzed. As shown in Fig. 2A and B, LPS significantly increased intracellular ROS production and NADPH oxidase activity in macrophages. The increased ROS levels and NADPH oxidase activity observed under LPS activation were markedly attenuated with a NADPH oxidase inhibitor DPI administration. We next assessed whether Nox directly controlled inflammatory mediator in LPS-stimulated macrophages. As shown in Fig. 2C and D, DPI attenuated

Fig. 1. Nox4 and inflammatory mediators were induced by LPS in macrophages. RAW 264.7 cells were stimulated with or without LPS (1 $\mu \mathrm{g} / \mathrm{ml}$ ) for in d i c a te d periods, the in fla m matory protein expression and cytokines production were analyzed as d e s cribed in Materials and Methods, respectively; (A) Curve chart $\mathrm{s}$ h o w e d quantitative analysis of Nox $4, \beta$-actin
B
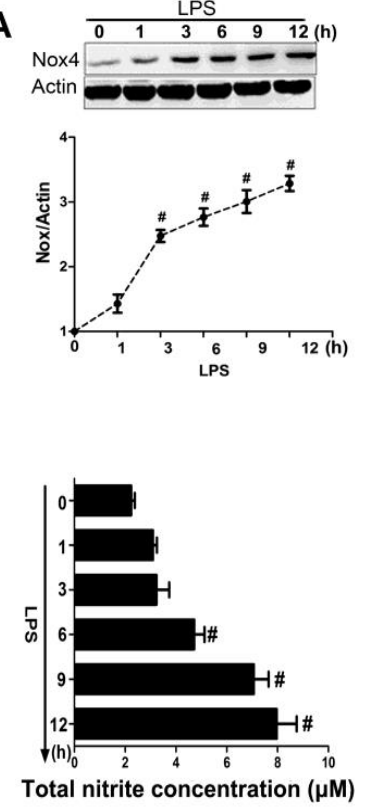

E

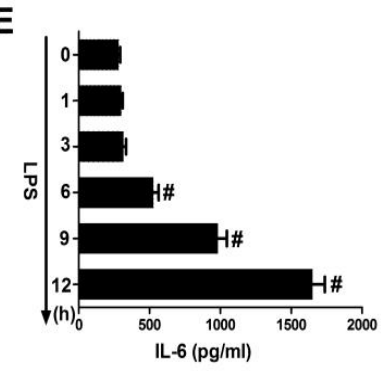

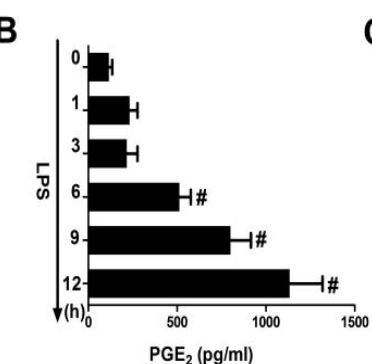

\section{C}

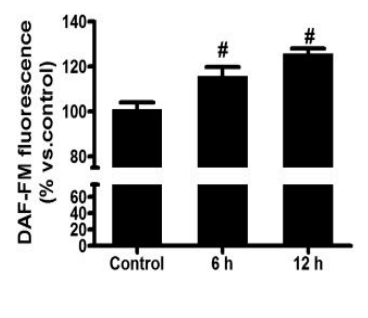

D
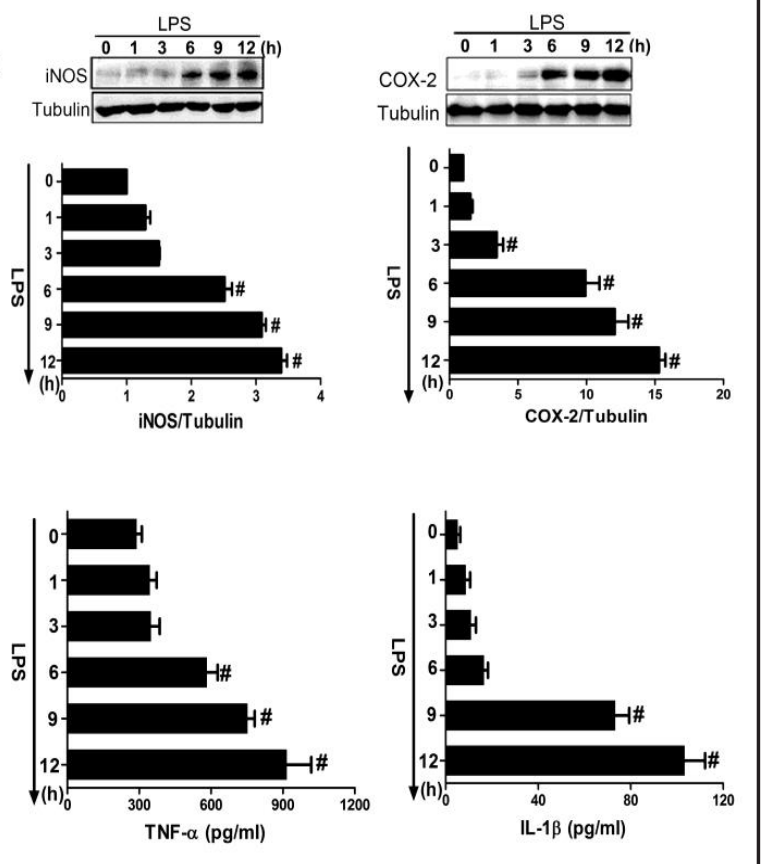

was used as loading control. (B) Bar graphs showed quantitative analysis of PGE 2 production; (C) NO production was measured using DAF-FM fluorescence and was presented as $\%$ of the control, total nitrite concentration was measured using Griess reagent; (D) iNOS and COX-2 expression were examined by western blot, tubulin was used as loading control; (E) Bar graphs showed quantitative analysis of inflammatory cytokines (IL-6, TNF- $\alpha$, IL-1 $\beta$ ). Data were shown means \pm SEM; $n=6$, ${ }^{*} p<0.05$, compared with unstimulated cells. 


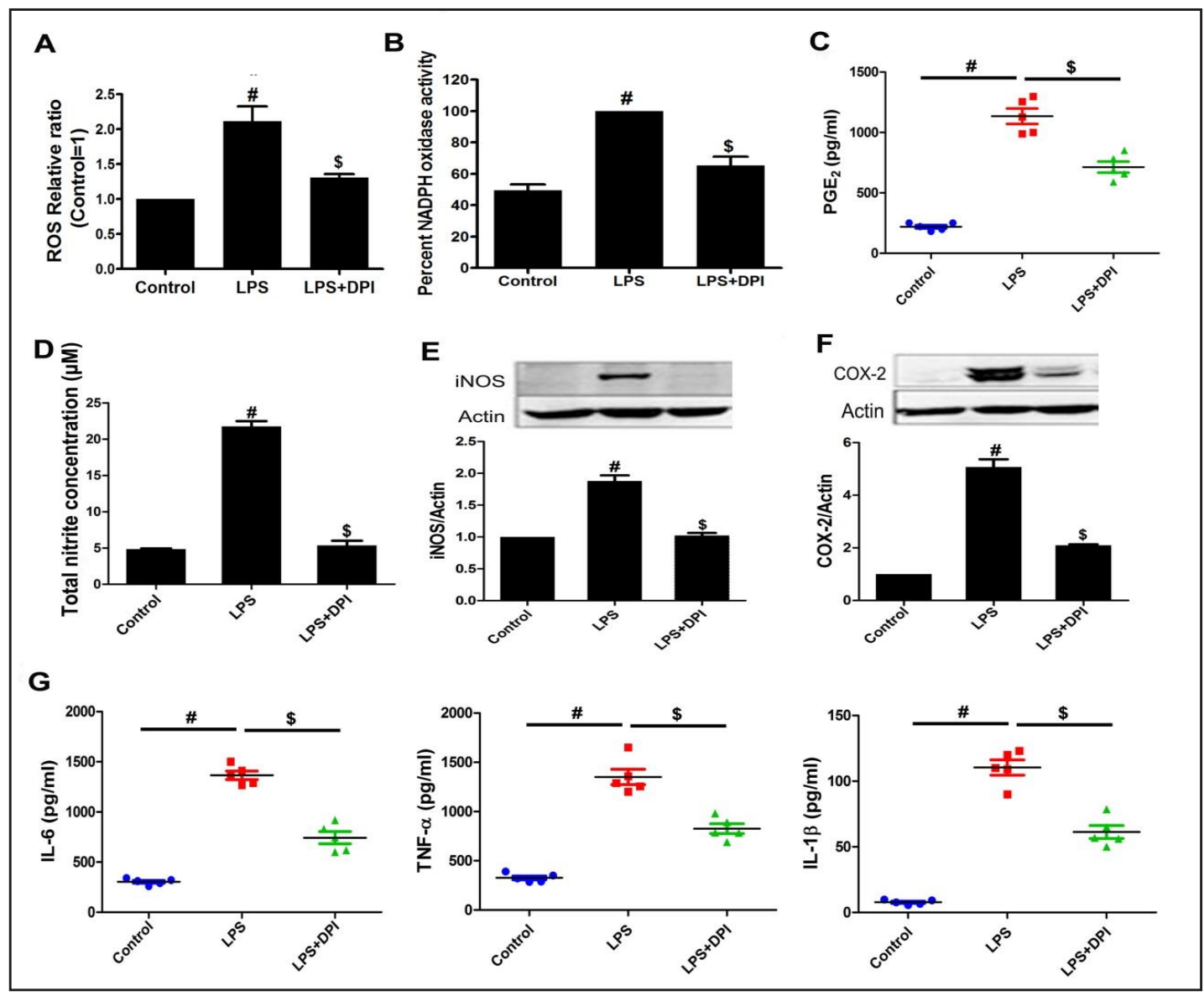

Fig. 2. NADPH oxidase inhibitor DPI ameliorated LPS-induced inflammatory response in RAW264.7. RAW264.7 cells were incubated with DPI $(10 \mu \mathrm{M})$, then stimulated with or without LPS (1 $\mu \mathrm{g} / \mathrm{ml})$ for 4 h, ROS production and NADPH oxidase activity was analyzed; Bar graphs showed quantitative analysis of intracellular ROS production (A) and NADPH oxidase activity (B). RAW264.7 cells were stimulated with or without LPS $(1 \mu \mathrm{g} / \mathrm{ml})$ for $12 \mathrm{~h}$, the inflammatory protein expression and cytokines production were analyzed as described in Materials and Methods, respectively; Bar graphs showed quantitative analysis of PGE ${ }_{2}$ production (C), total nitrite concentration (D), iNOS expression (E), COX-2 expression (F), and inflammatory cytokines (IL-6, TNF- $\alpha$, IL-1 $\beta$ ) generation (G); $\beta$-actin was used as loading control. Data were shown means \pm SEM; $n=6,{ }^{\#} p<0.05$, compared with unstimulated cells, ${ }^{\$} \mathrm{p}<0.05$, compared with LPS-stimulated cell.

LPS-induced $\mathrm{PGE}_{2}$ and total nitrite production. Meanwhile, DPI also markedly induced a significant reduction in iNOS and COX-2 expression in LPS-stimulated macrophages (Fig. 2E and F). In addition, LPS-mediated inflammatory cytokines (IL-6, TNF- $\alpha$, IL-1 $\beta$ ) production was also been attenuated by DPI (Fig. 2G).

To further evaluate the direct role of Nox 4 on LPS-induced inflammation, we transduced lentiviruses harboring short hairpin RNA (shRNA) for Nox4 into macrophages to deplete Nox4 expression (Fig. 3A). We observed that the increased NADPH oxidase activity and ROS levels under LPS activation were markedly attenuated with lentiviral Nox4 shRNA knockdown (Fig. 3B and C). Accordingly, knockdown of Nox4 resulted in ameliorated LPSinduced total nitrite production, consistent with the effect of e-PTIO, a NO scavenger (Fig. 3D). Meanwhile, the release of inflammatory mediator $\mathrm{PGE}_{2}$ (Fig. 3E) and the expression of iNOS and COX-2 (Fig. 3F) were attenuated by Nox 4 knockdown. The production of cytokines (IL-6, TNF- $\alpha$, IL-1 $\beta$ ) was also down-regulated (Fig. 3G).

Conversely, we transduced lentiviruses harboring Nox4 cDNA to upregulate Nox4 expression. As shown in Fig. 4A, Nox4 expression in lentiviral Nox4 cDNA treatment cells was 


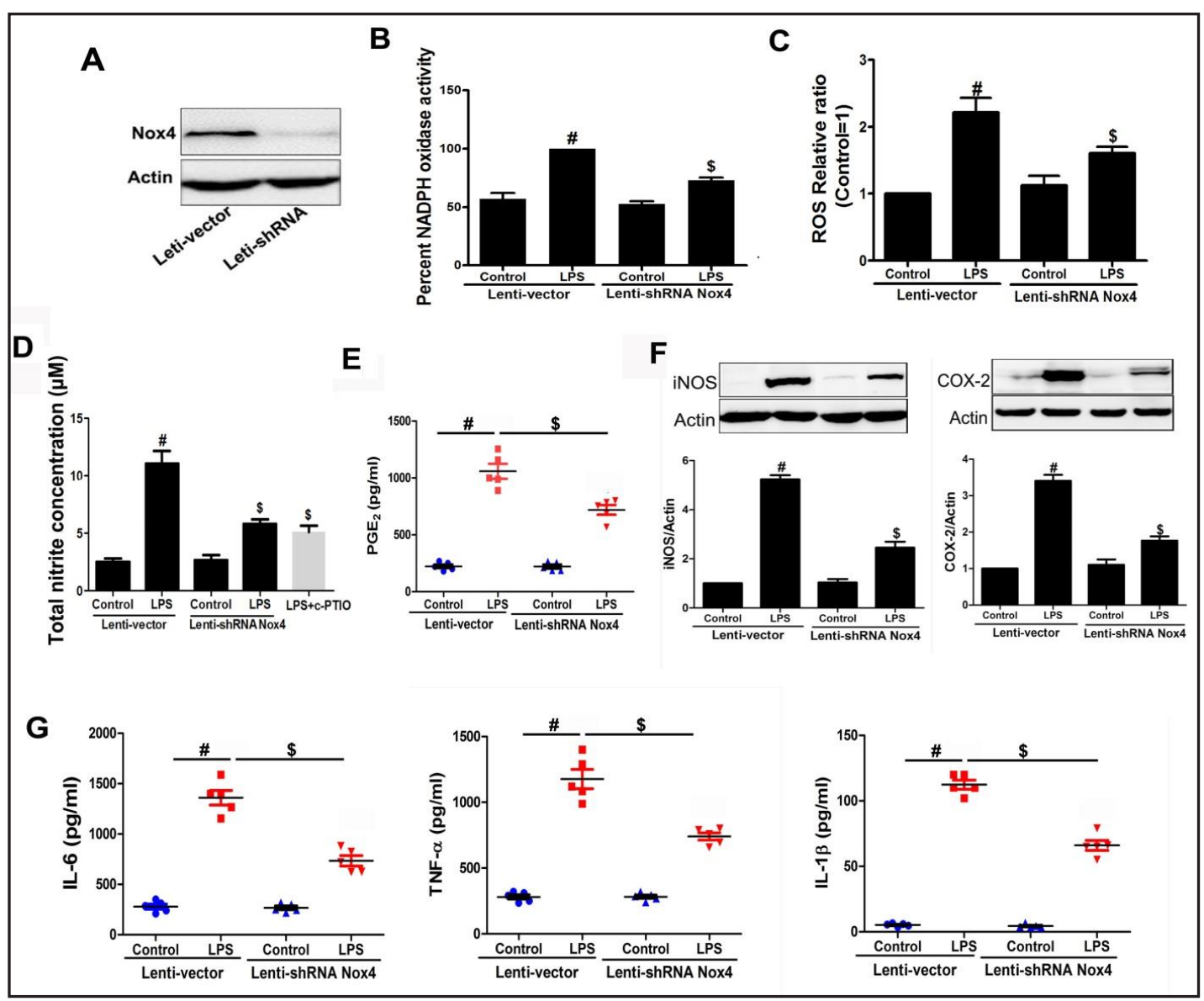

Fig. 3. Nox4 knockdown inhibited LPS-induced inflammatory response. RAW264.7 cells were transfected with lentiviral shRNA-Nox 4 or lentiviral vector, then stimulated with or without LPS ( $1 \mu \mathrm{g} / \mathrm{ml})$ for $4 \mathrm{~h}$, intracellular ROS production and NADPH oxidase activity were analyzed as described in Materials and Methods, respectively. Representative picture showed bands of Nox4 expression (A), Bar graphs showed quantitative analysis of NADPH oxidase activity (B) and intracellular ROS production (C); RAW264.7 cells were pretreated with c-PTIO $(50 \mu \mathrm{M})$ and stimulated with or without LPS $(1 \mu \mathrm{g} / \mathrm{ml})$ for $12 \mathrm{~h}$, the inflammatory protein expression and cytokines production were analyzed as described in Materials and Methods, respectively; Bar graphs showed quantitative analysis of total nitrite concentration (D) and PGE ${ }_{2}$ production (E), iNOS and COX-2 expression (F), inflammatory cytokines (IL-6, TNF- $\alpha$, IL-1 $\beta$ ) generation (G); $\beta$-actin was used as loading control. Data were shown means \pm SEM; $n=6$, ${ }^{\#} p<0.05$, compared with unstimulated cells, ${ }^{\$} p<0.05$, compared with LPS-stimulated cell.

gradually increased along with extend of LPS treatment time as compared to control vector cells. The overexpression of Nox4 exaggerated LPS-mediated NADPH oxidase activity and ROS production (Fig. 4B and C). Meanwhile, although overexpression of Nox4 did not affect inflammatory markers at baseline, it significantly exaggerated LPS-induced inflammatory mediators (total nitrite, PEG $_{2}$, iNOS, and COX-2) (Fig. 4D and E) and cytokines (IL-6, TNF- $\alpha$, IL-1 $\beta$ ) productions (Fig. 4F) in macrophages. These results demonstrated that Nox4 might be responsible for inflammatory mediators in macrophages.

\section{Nox4 mediates LPS-induced signaling pathway activation}

We further checked the roles of NADPH oxidase on LPS-mediated PI3K/Akt and mitogenactivated protein kinase (MAPK) signaling activation, which are involved in LPS-mediated inflammatory mediators in macrophage [22]. The p-GSK3 $\beta$ and p-Akt were time-dependently suppressed by DPI or lentiviral Nox4 shRNA treatment in LPS-stimulated macrophages (Fig. 


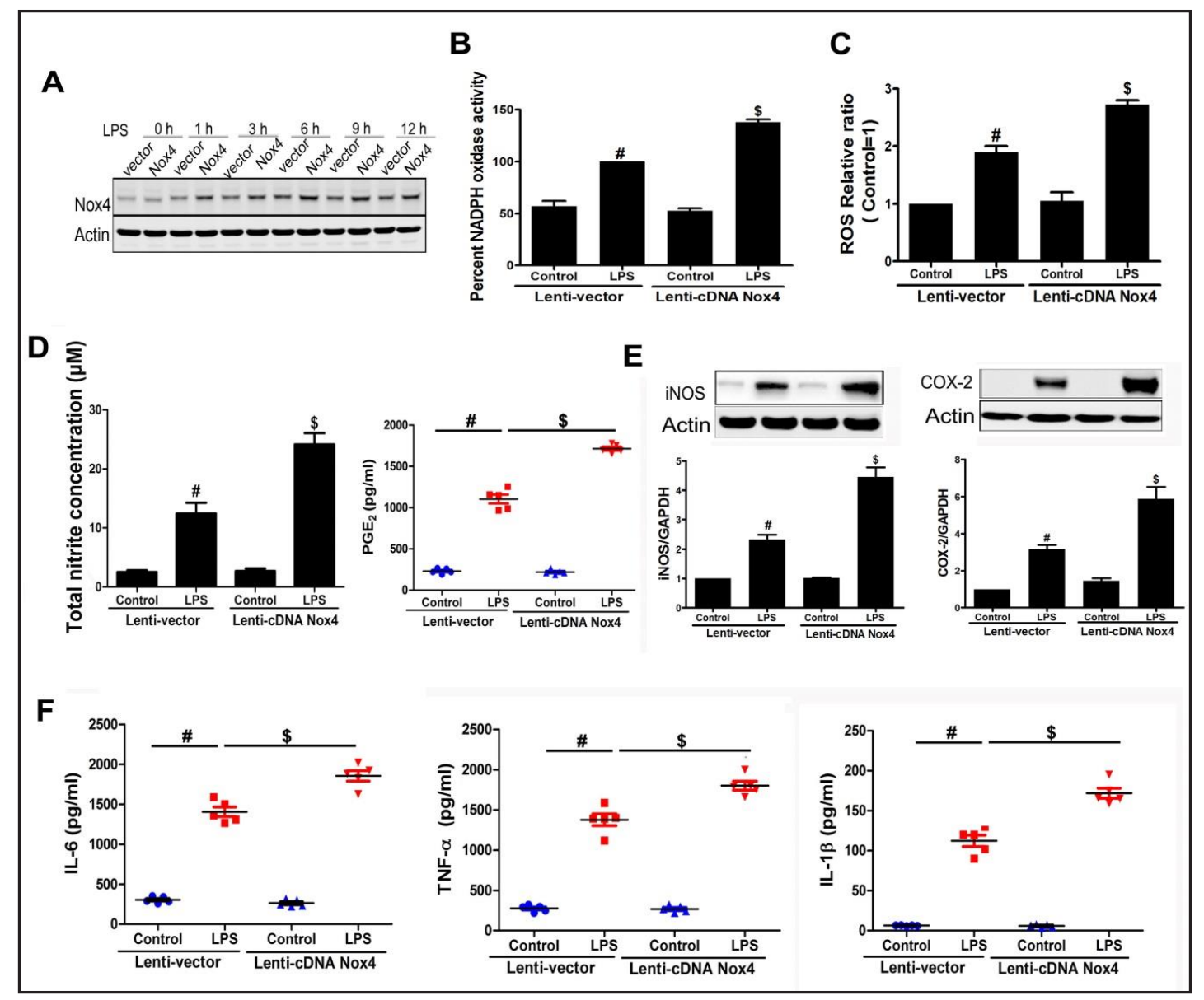

Fig. 4. Overexpression Nox4 exacerbated inflammation response in LPS-induced macrophage. RAW264.7 cells were transfected with lentiviral cDNA-Nox4 or lentiviral vector, then stimulated with or without LPS $(1 \mu \mathrm{g} / \mathrm{ml})$ for $4 \mathrm{~h}$, intracellular ROS production and NADPH oxidase activity were analyzed as described in Materials and Methods, respectively. Representative images of Western blotting for the Nox4 (A), Bar graphs showed quantitative analysis of intracellular NADPH oxidase activity (B), ROS production (C). RAW264.7 cells were stimulated with or without LPS $(1 \mu \mathrm{g} / \mathrm{ml})$ for $12 \mathrm{~h}$, the inflammatory protein expression and cytokines production were analyzed as described in Materials and Methods, respectively; Bar graphs showed quantitative analysis of total nitrite concentration and $\mathrm{PEG}_{2}$ production (D), iNOS and COX-2 expression (E), and the levels of inflammatory cytokines (IL-6, TNF- $\alpha$, and IL-1 $\beta$ ) (F); Data were shown means \pm SEM; $n=6$, ${ }^{\#} \mathrm{p}<0.05$, compared with unstimulated cells; ${ }^{\$} \mathrm{p}<0.05$, compared with LPS-stimulated cells.

$5 \mathrm{~A}$ and B). Meanwhile, the level of p-p38 was also time-dependently decreased by lentiviral Nox4 shRNA treatment, but there was almost no change in p-ERK level (Fig. 5C and D). Furthermore, RAW264.7 cells were treated with LY294002 (a PI3K inhibitor) or NAC (5 mM) markedly reduced LPS-mediated nitrite production (Fig. 5E). Together, these data supported a pivotal role for Nox4 in mediating inflammatory response in LPS-stimulated macrophages.

\section{$\mathrm{CSE} / \mathrm{H}_{2} \mathrm{~S}$ system negatively regulates inflammatory response through mediated Nox4} activation

Endogenous $\mathrm{H}_{2} \mathrm{~S}$ production is mainly attributed to CSE in macrophages $[8,23]$. As shown in Fig. 6A, LPS stimulation rapidly induced CSE protein expression and $\mathrm{H}_{2} \mathrm{~S}$ production in macrophages. We then determined the role of CSE/H2S on LPS-triggered inflammatory mediators. Thus, we knocked down CSE expression by siRNA in macrophages, which caused the decrease of $\mathrm{H}_{2} \mathrm{~S}$ production in LPS-stimulated macrophages (Fig. 6B). Interestingly, CSE silencing enhanced Nox4 expression, this could be markedly reduced by 


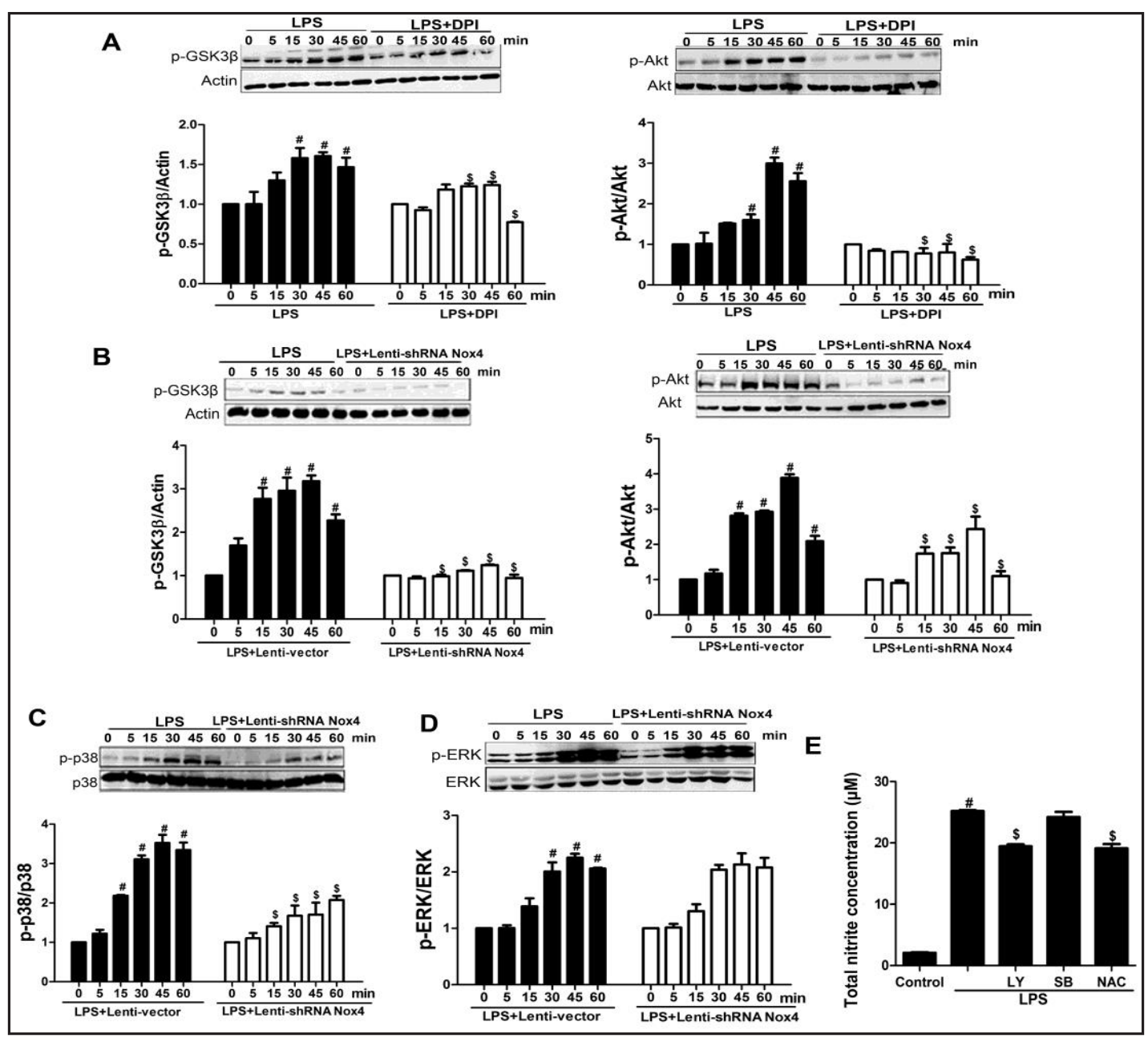

Fig. 5. Nox4 modulated LPS-induced MAPK and Akt signaling activation. RAW264.7 cells were pretreated with DPI, then stimulated with or without LPS $(1 \mu \mathrm{g} / \mathrm{ml})$ for indicated periods, Western blot and quantitative analysis for the levels of p-GSK3 $\beta$ /actin, p-Akt/Akt (A), RAW264.7 cells were transfected with lentiviral shRNA-Nox4 or scrambled shRNA, then stimulated with or without LPS $(1 \mu \mathrm{g} / \mathrm{ml})$ for indicated periods, Western blot and quantitative analysis for the levels of p-GSK3ß/actin and p-Akt/Akt (B), p-p38/p38 (C), and p-ERK/ERK (D). RAW264.7 cells were pretreated with LY294002 (10 $\mu \mathrm{M})$, SB203580 (10 $\mu \mathrm{M})$, or NAC $(5 \mathrm{mM})$, then stimulated with or without LPS $(1 \mu \mathrm{g} / \mathrm{ml})$ for $12 \mathrm{~h}$, the total nitrite concentration was analyzed (E); Data were shown means \pm SEM; $n=6$, ${ }^{*} \mathrm{p}<0.05$, compared with unstimulated cells; ${ }^{\$} \mathrm{p}<0.05$, compared with LPS-stimulated cells.

exogenous administration of NaHS (Fig. 6C). Consitantly, NADPH oxidase activity could be markedly reduced by NaHS as well as be decreased by CAT or SOD, a scavenger of $\mathrm{O}^{-2} \mathrm{or}_{2} \mathrm{O}_{2}$ (Fig. 6D). In addition, CSE silencing also enhanced LPS-triggered inflammatory response, as evidenced by increased inflammatory mediators (total nitrite, iNOS and COX-2) (Fig. $6 \mathrm{E}$ and F) and inflammatory cytokine TNF- $\alpha$ production (Fig. 6G). Instead, we transduced lentiviruses harboring CSE cDNA to upregulate CSE expression, which caused the increase of $\mathrm{H}_{2} \mathrm{~S}$ production in LPS-stimulated macrophages (Fig. 7A and B). Notably, CSE overexpression by lentivirus markedly reduced Nox4 expression and NADPH oxidase activity (Fig. 7C and D). Accordingly, CSE overexpression profoundly inhibited inflammatory mediators (total nitrite, iNOS, and COX-2) (Fig. 7E, F and G) and inflammatory cytokine TNF- $\alpha$ production (Fig. $7 \mathrm{H})$. Collectively, LPS stimulation upregulated CSE/H2S system, which formed a negative feedback loop to inhibit LPS-induced inflammatory responses in macrophages through inhibiting Nox4-ROS. 


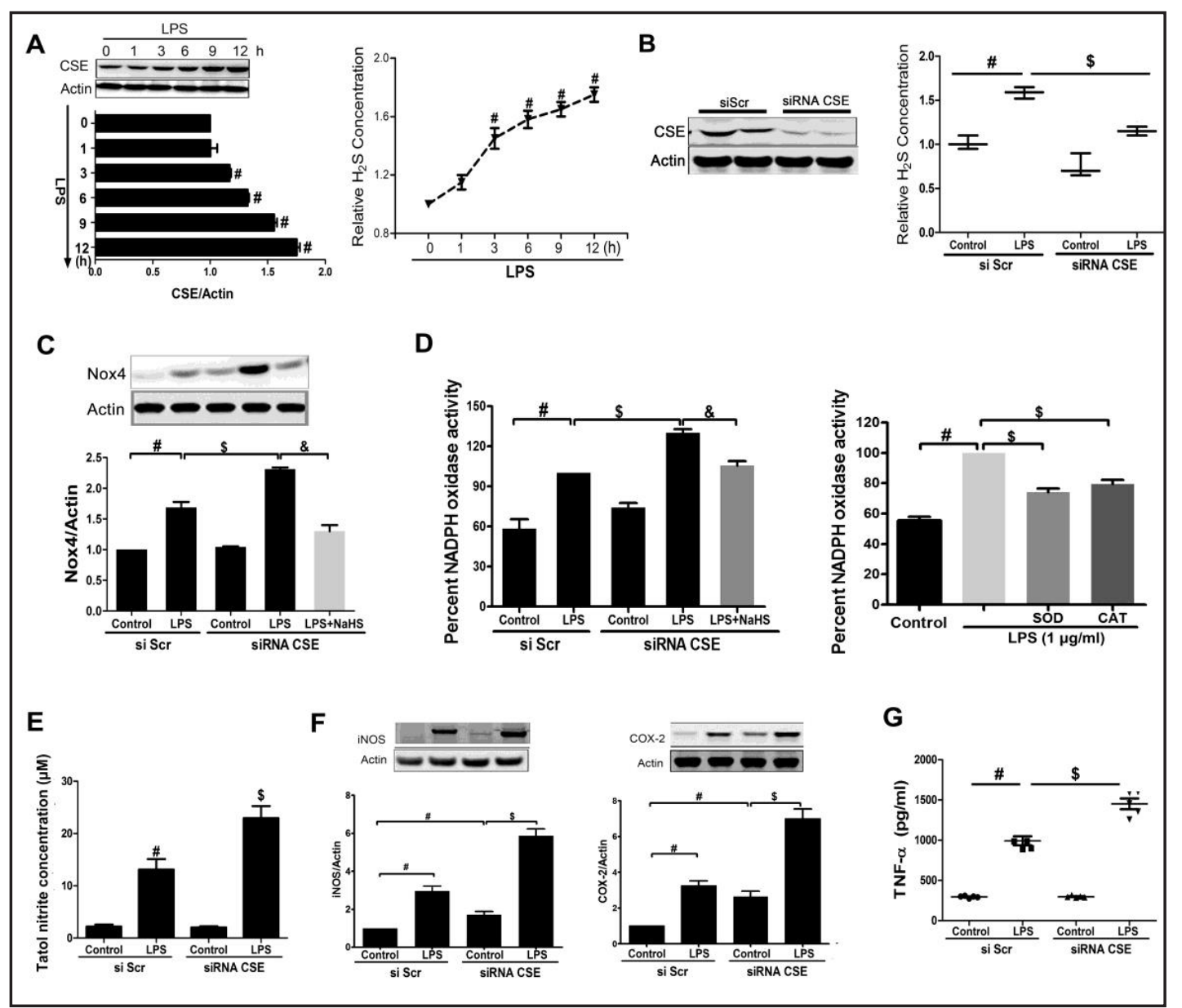

Fig. 6. $\mathrm{CSE} / \mathrm{H}_{2} \mathrm{~S}$ system negatively regulated inflammatory mediators. (A) RAW264.7 cells were stimulated with or without LPS $(1 \mu \mathrm{g} / \mathrm{ml})$ for indicated periods, bar graph showed quantitative analysis of CSE expression and $\mathrm{H}_{2} \mathrm{~S}$ concentration. (B) RAW264.7 cells were transfected with CSE siRNA or scrambled siRNA (si Scr), then were stimulated with or without LPS $(1 \mu \mathrm{g} / \mathrm{ml})$, representative images of Western blotting for the CSE, and quantitative analysis for the levels of $\mathrm{H}_{2} \mathrm{~S}$. (C-D) After transfected with CSE siRNA or si Scr, cells were treated with NaHS $(150 \mu \mathrm{M})$ or cells pretreated with SOD $(1000 \mathrm{U} / \mathrm{ml}), \mathrm{CAT}(1000 \mathrm{U} / \mathrm{ml})$, then were stimulated with or without LPS $(1 \mu \mathrm{g} / \mathrm{ml})$, bar graphs showed Nox4 expression (C), NADPH oxidase activity (D). (E-G) RAW264.7 cells were transfected with CSE siRNA or si Scr, then were stimulated with or without LPS $(1 \mu \mathrm{g} / \mathrm{ml})$, quantitative analysis for total nitrite concentration (E), iNOS and COX-2 expression $(F)$, inflammatory cytokine TNF- $\alpha$ production (G); Data were shown means \pm SEM; $n=6$, ${ }^{\#} p<0.05$, compared with unstimulated cells; ${ }^{\$} \mathrm{p}<0.05$, compared with LPS-stimulated cells.

Nox4 knockdown protects against LPS-induced septic shock

To evaluate the role of Nox4 in LPS-mediated septic shock, we delivered lentiviral Nox4 shRNA to generate Nox4 knockdown mouse models. Nox4 knockdown mice increased survival rates compared to mice with a single injection LPS treatment (Fig. 8A). This was associated with less lung injury in the Nox4 knockdown mice (Fig. 8B). In agreement with this, lentivirus-mediated Nox4 knockdown mice markedly decreased the expression of Nox4 in lungs (Fig. 8C), accompanied by decreasing iNOS expression (Fig. 8D). Furthermore, production of serum inflammatory cytokines (IL-6, TNF- $\alpha$, and IL-1 $\beta$ ) (Fig. 8E) markedly decreased in the Nox4 knockdown mice. Together, these data supported that Nox4 played a critical role in inflammatory process in septic mice.

\section{KARGER}




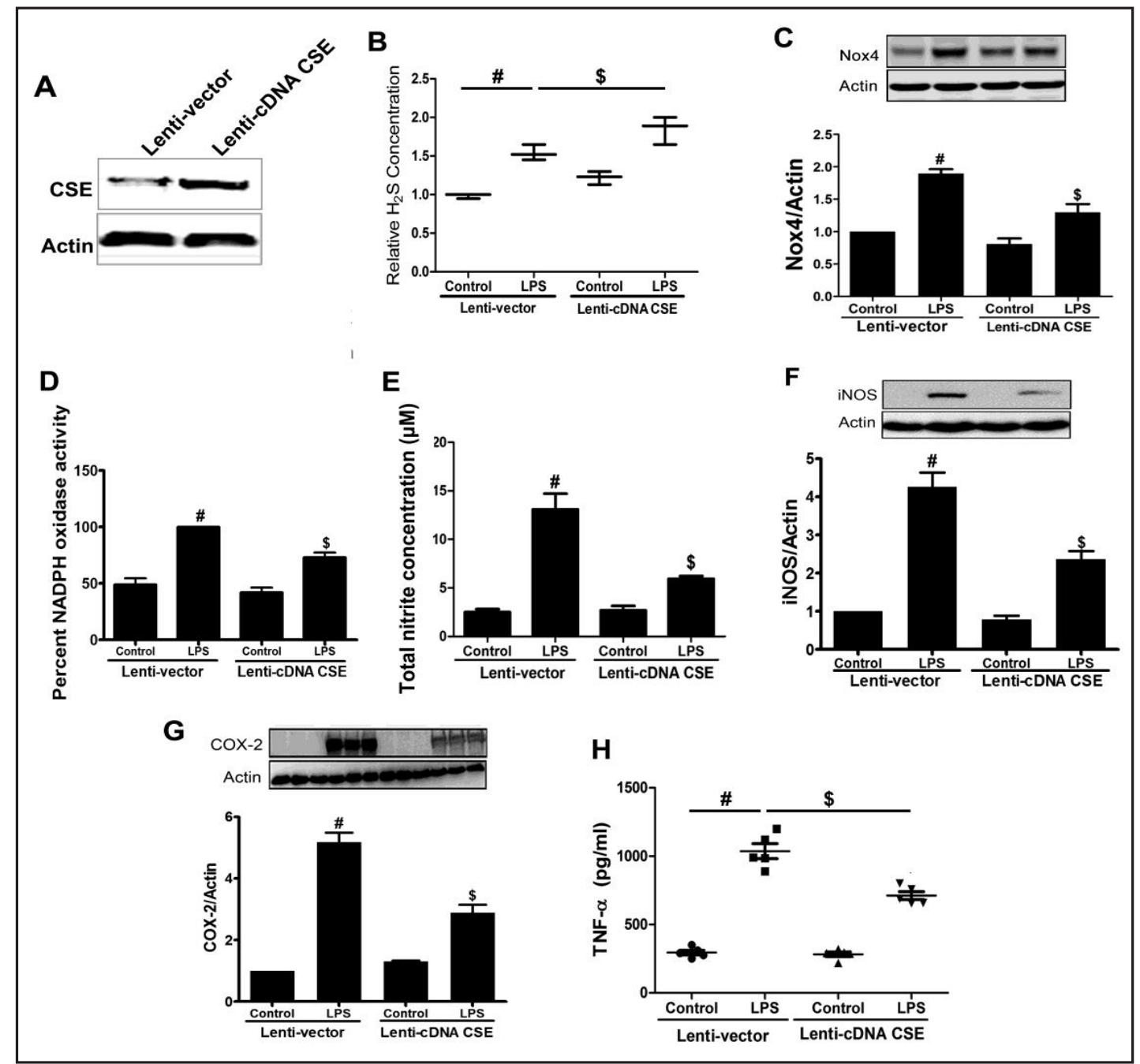

Fig. 7. Overexpression CSE suppressed LPS-induced inflammation response through mediated Nox4 activation. RAW264.7 cells were incubated with lentiviral CSE cDNA or lentiviral vector, then stimulated with or without LPS (1 $\mu \mathrm{g} / \mathrm{ml})$, bar graphs show CSE expression (A), $\mathrm{H}_{2} \mathrm{~S}$ level (B), Nox4 expression (C), NADPH oxidase activity (D), total nitrite concentration (E), iNOS expression (F) COX-2 expression (G), and inflammatory cytokine TNF- $\alpha$ production $(H)$; Data were shown means $\pm S E M ; n=6,{ }^{\#} p<0.05$, compared with unstimulated cells; ${ }^{\$} \mathrm{p}<0.05$, compared with LPS-stimulated cells.

\section{CSE $/ \mathrm{H}_{2} \mathrm{~S}$ system is critical for inhibition of septic shock}

Next we investigated whether $\mathrm{CSE} / \mathrm{H}_{2} \mathrm{~S}$ negatively regulated Nox4-mediated inflammatory responses. We used LPS-induced septic shock model in WT and CSE ${ }^{-/}$mice. LPS administration could induce CSE expression in major organs and serum $\mathrm{H}_{2} \mathrm{~S}$ concentration in WT mouse. $\mathrm{CSE}^{-/}$mice showed the absence of CSE protein, and serum $\mathrm{H}_{2} \mathrm{~S}$ concentration induced by LPS didn't elevated much compared with WT mice (Fig. 9A and B). Compared with the LPS-stimulated WT mice, the LPS-stimulated $\mathrm{CSE}^{-/-}$mice increased lung injury (Fig. 9C). More importantly, CSE $/$ mice markedly increased Nox 4 expression (Fig. 9D) and NADPH oxidase activity (Fig. 9E) as well as ROS production (Fig. 9F) in lungs tissues. In agreement with this, LPS-treated CSE $/$ mice significantly increased the production of serum IL-1 $\beta$ (Fig. $9 \mathrm{G})$. These observations indicated that $\mathrm{CSE} / \mathrm{H}_{2} \mathrm{~S}$ negatively modulated LPS-mediated Nox4 and inflammatory response. 


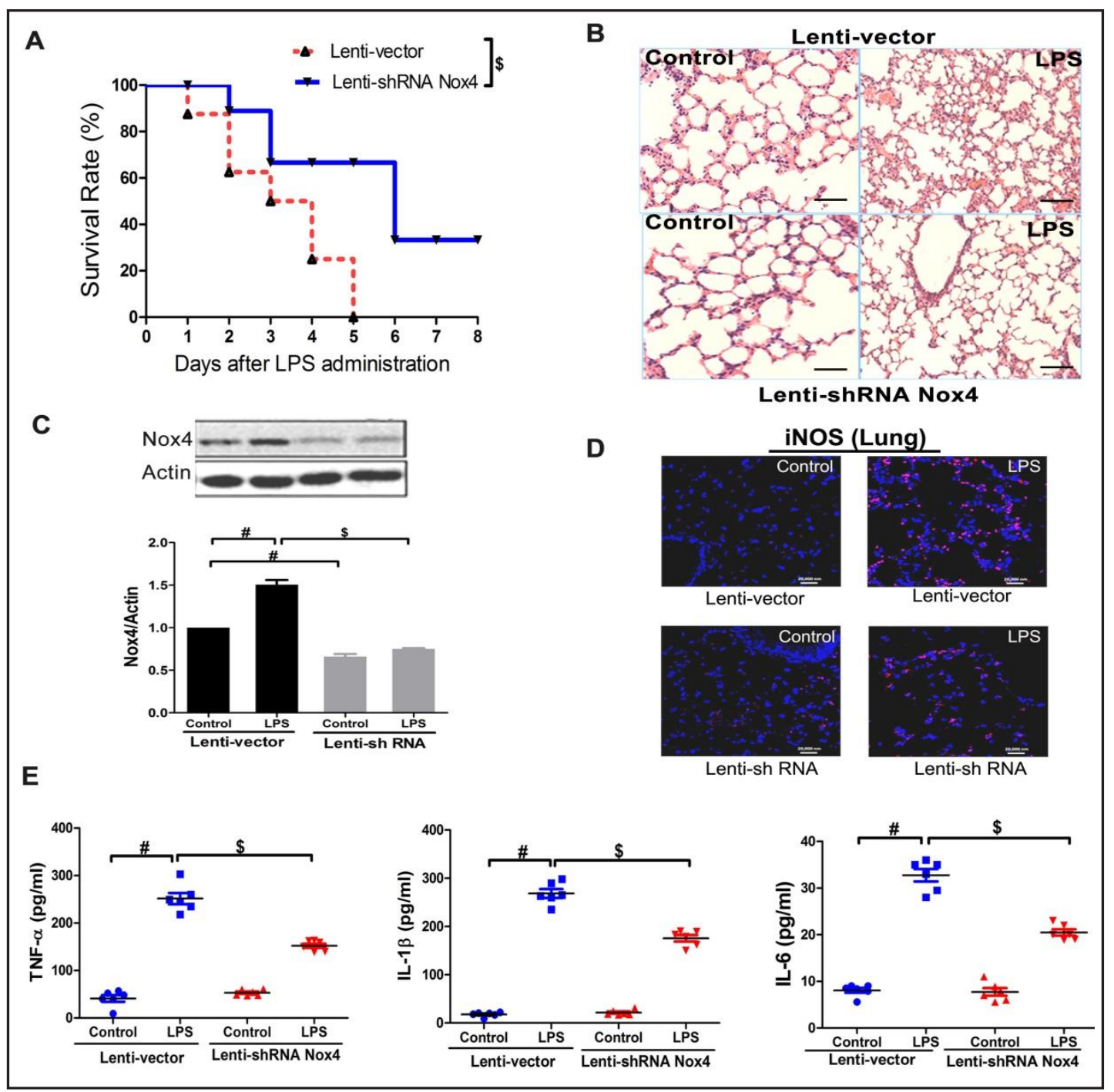

Fig. 8. Nox4 knockdown protected against LPS-induced septic shock. After delivered lentiviral Nox4 shRNA or vector by intravenous injection 5 times to generate Nox4 knockdown mice, then these mice are intraperitoneally (i.p.) injected with LPS to monitor the survival rates $(n=9)(A)$, lung injury by H\&E staining (B), Nox4 expression by western blot (C), iNOS expression by Immunofluorescence in lungs (D), and inflammatory cytokines (IL-6, TNF- $\alpha$, and IL-1 $\beta$ ) production in plasma (E); Data were shown means \pm SEM; $\mathrm{n}=7$, ${ }^{*} \mathrm{p}<0.05$, compared with control mice; ${ }^{\$} \mathrm{p}<0.05$, compared with LPS-induced mice.

\section{Discussion}

Previous studies have documented that elevated $\mathrm{H}_{2} \mathrm{~S}$ suppress inflammatory response on macrophages or mouse to maintain immune homeostasis [24-26]. In this study, we identified Nox4-ROS as a key signaling pathway that exaggerated inflammatory response in macrophages or septic mouse. Meanwhile, our study also revealed that $\mathrm{CSE} / \mathrm{H}_{2} \mathrm{~S}$ system modulated inflammatory response through mediating Nox4 signaling in LPS-induced macrophages or septic mouse.

ROS generated under physiological conditions maintain cell homeostasis, but their excessive generation can activate redox-sensitive transcription factors, thereby provoking 


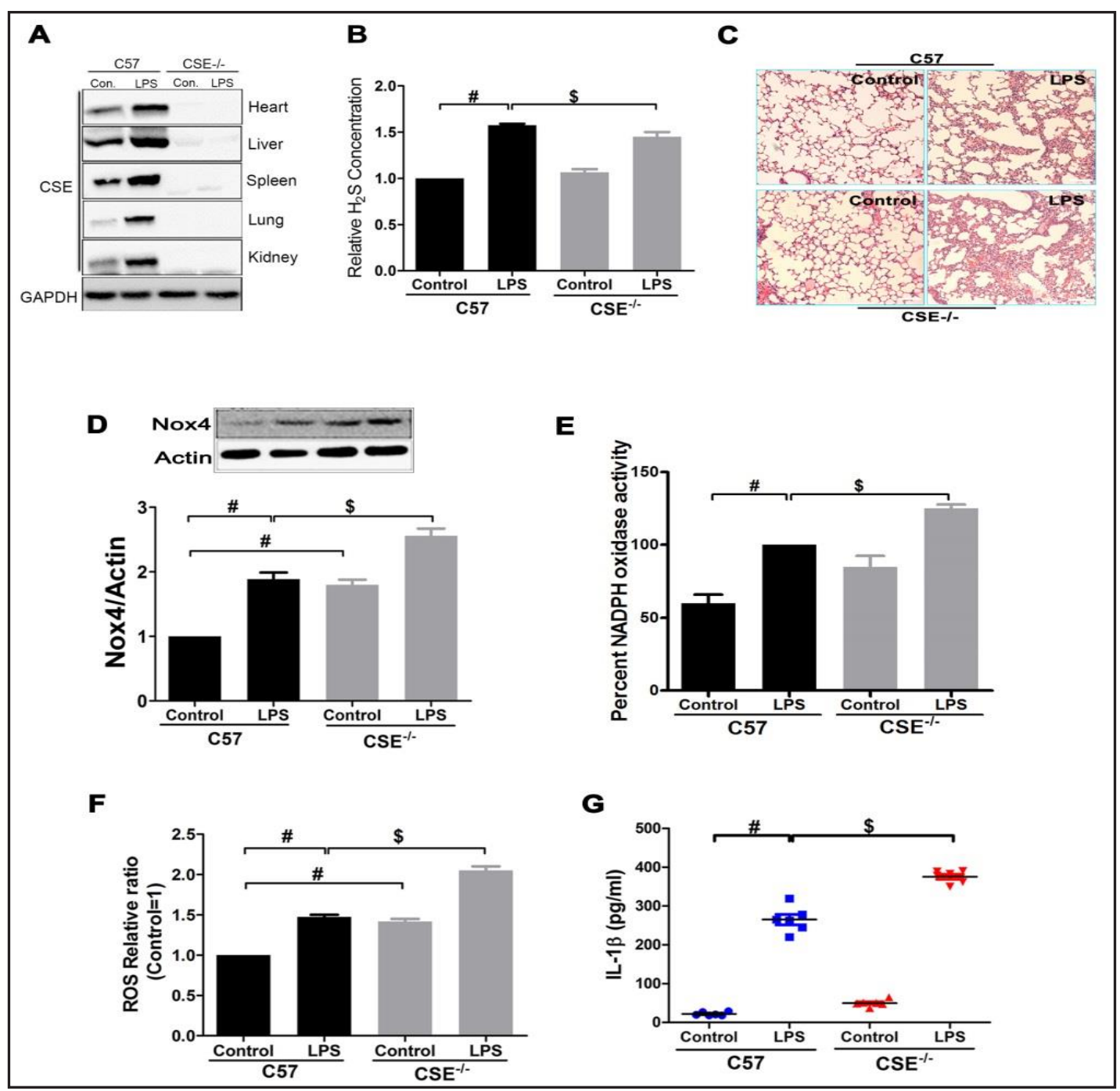

Fig. 9. $\mathrm{CSE} / \mathrm{H}_{2} \mathrm{~S}$ system was critical for inhibition of septic shock. The CSE ${ }^{-/}$or WT mice were intraperitoneally (i.p.) injected with LPS to dectect the CSE expression in main major orgens (A), $\mathrm{H}_{2} \mathrm{~S}$ levels (B), lung injury by H\&E staining (C), Nox4 expression (D), NADPH oxidase activity (E), ROS production in lungs (F), inflammatory cytokines IL-1 $\beta$ production in plasma $(G)$; Data were shown means $\pm S E M ; n=7$, \#p<0.05, compared with control mice; ${ }^{\$} \mathrm{p}<0.05$, compared with LPS-induced mice.

inflammatory response $[27,28]$, thus contributing to the pathogenesis of sepsis. The NADPH oxidases are a major source of intracellular ROS generation in macrophages [29]. Meanwhile, NADPH oxidase-dependent ROS played a detrimental role in lethal innate immune response in sepsis $[4,30]$. The role of oxidative stress in septic pathogenesis has been well appreciated [3, 4]; however, the mechanisms by which oxidative stress contributed to pathogenesis were not well defined. There were at least seven isoforms of NADPH oxidase that have been identified, termed Nox1-Nox5, DUOX1, and DUOX2, and most of them were detected in immune cells, including macrophages [31]. Nox4 was constitutively active, the elevated Nox4 expression directly translated to increase ROS production [32]. Increasing evidences demonstrated that Nox4 played a detrimental role in process of inflammatory diseases, including sepsis $[3,30,33]$. Here, our results clearly showed that Nox4 was significantly increased in LPSinduced septic mice, which was accompanied by increased inflammatory mediators and inflammatory cytokines production. Thus, there is not much doubt that Nox 4 played a primary role in LPS-mediated inflammatory response and supported the recent findings that Nox4 
Fig. 10. Proposed working model by which endogenous hydrogen sulfide ameliorates NOX4 induced oxidative stress in LPS-stimulated macrophages and mice. Endogenous hydrogen sulfide inhibited LPS-mediated upregulation of inflammatory mediators by direct inhibition of Nox4-ROS signaling pathway.

enhancement played a pivotal role in the regulation of inflammatory responses [30, 34]. Pharmacologic or genetic inhibition of Nox4 limited inflammatory response and inflammatory cytokines release

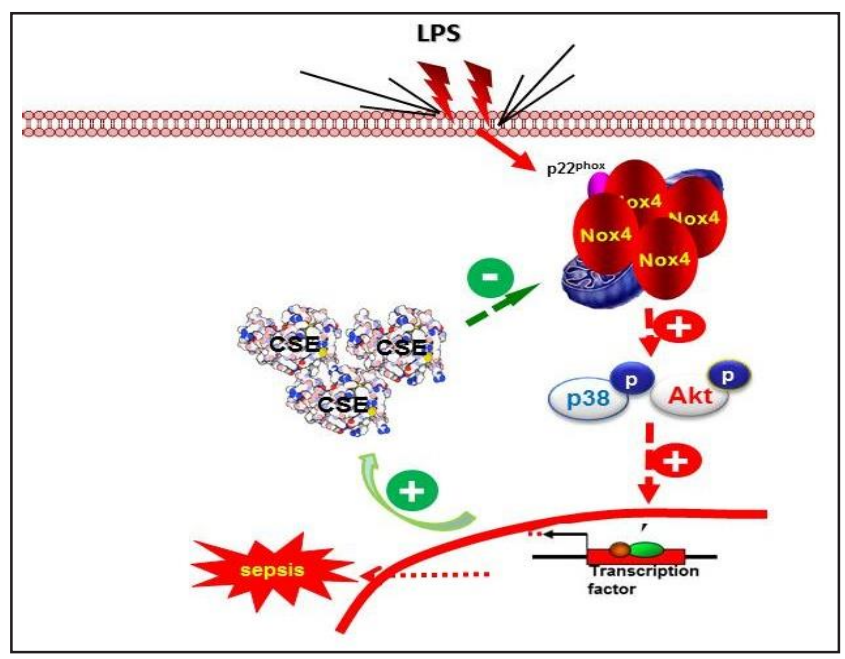
$[30,35]$. Accordingly, lentivirus-

mediated Nox4 knockdown showed significantly improved survival along with decreased production of inflammatory mediators in LPS-induced sepsis. Taken together, our results indicated that Nox4 positively regulated inflammatory activation and suggested that Nox4 might be a potential target for treatment of inflammatory diseases.

Over the years, $\mathrm{H}_{2} \mathrm{~S}$ is emerging as an important mediator in acute and chronic inflammation [8]. It has been reported that the increased $\mathrm{H}_{2} \mathrm{~S}$ circulation detected in the burn injury [36] and its levels correlated with inflammatory and clinical indices in rheumatoid arthritis patients [37]. Moreover, multiple lines of studies, in multiple experimental models, showing that therapeutic elevation of $\mathrm{H}_{2} \mathrm{~S}$ concentrations or $\mathrm{H}_{2} \mathrm{~S}$ donors can exert anti-inflammation and decrease the mortality caused by endotoxemia [3840]. We found that CSE expression was significantly increased in LPS-induced macrophage, which were accompanied by increased inflammatory mediators and inflammatory cytokines production. Similarly, CSE $/ \mathrm{H}_{2} \mathrm{~S}$ system was increased in abundance in LPS-induced septic mice. Those results suggested that the control of $\mathrm{H}_{2} \mathrm{~S}$ synthesis through the induced CSE associated with the regulation of inflammatory signaling. Furthermore, we demonstrated that $\mathrm{CSE}^{-/-}$mice were more susceptible to LPS-induced sepsis accompanied by enhanced inflammatory mediators production. Indeed, on the contrary, overexpression CSE inhibited inflammatory response in LPS-induced macrophage. It is therefore possible that the upregulation of $\mathrm{H}_{2} \mathrm{~S}$ synthesis, previously observed in LPS-induced macrophage, may represent a novel endogenous mechanism for limiting inflammation in sepsis.

Numerous studies have demonstrated that NADPH oxidase-dependent ROS played a crucial role in the pathophysiology of sepsis by regulating immune cell activation and ending organ injury $[29,30]$. Previous findings have suggested that many negative effectors are induced by inflammatory stimuli, which then functioned as feedback loops to dampen inflammation or induce endotoxin tolerance $[41,42]$. For example, exposure of macrophages to LPS resulted in vascular endothelial growth factor expression, which restrained TLR4NF- $\kappa B$ activation by regulating the PI3-kinase-Akt signaling pathway and SOCS1 expression [41]. In previous study, we have clearly demonstrated that $\mathrm{H}_{2} \mathrm{~S}$, a reducing agent and an antioxidant molecule, is also involved in modulation of intracellular ROS production in a Nox4-dependent manner [20]. An emerging body of evidence suggested that the regulation of CSE expression was subject to redox-dependent mechanisms and was promoted in response to a pro-oxidative cellular environment. In the present study, we provided evidences that upregulation of CSE $/ \mathrm{H}_{2} \mathrm{~S}$ system in LPS-induced macrophage limited inflammation in sepsis through mediating Nox4. Meanwhile, knockdown of CSE enhanced LPS-induced inflammatory response in macrophages, whereas CSE overexpression reduced inflammatory mediators in macrophages. These observations were consistent with the previous notion that Nox4 was a positive transcriptional regulator of CSE expression and proposed that it might in turn 


\section{Cellular Physiology Cell Physiol Biochem 2018;47:458-474 \begin{tabular}{l|l} 
and Biochemistry Published online:May 24, 2018 & $\begin{array}{l}\text { Do } 2018 \text { The Author(s). Published by S. Karger AG, Basel } \\
\text { www.karger.com/cpb }\end{array}$ \\
\hline
\end{tabular}}

Wang et al.: $\mathrm{H}_{2} \mathrm{~S}$ Modulates Inflammation Through Nox4 Activation

contribute to the regulation of $\mathrm{H}_{2} \mathrm{~S}$ production [43]. We further identified the upregulation of CSE/ $\mathrm{H}_{2} \mathrm{~S}$ system suppressed LPS-induced Nox4-ROS signaling cascade in macrophages.

Collectively, our findings demonstrated that Nox4-ROS signaling accelerated inflammation. Furthermore, up-regulation of $\mathrm{CSE} / \mathrm{H}_{2} \mathrm{~S}$ system biosynthesis in LPS-induced macrophage in turn restrained LPS-triggered inflammatory response by regulating Nox4ROS signaling activation (see working model in Fig. 10). This would suggest that therapeutic strategies designed to maintain $\mathrm{CSE} / \mathrm{H}_{2} \mathrm{~S}$ system or target components of the Nox 4 activation might be effective in a number of pathological contexts.

\section{Disclosure Statement}

The authors declare that they have no competing interests.

\section{Acknowledgements}

This work was supported by grants from National Natural Science Foundation of China (No. 81673428; 81330080), Shanghai Committee of Science and Technology of China (No. 14JC1401100), "Zhuo Xue" Talent Plan of Fudan University, a key laboratory program of the Education Commission of Shanghai Municipality (No. ZDSYS14005). Technology Development fund of Macau (FDCT (055/2016/A2 and 039/2016/A).

\section{References}

1 Balk RA: Systemic inflammatory response syndrome (SIRS): where did it come from and is it still relevant today? Virulence 2014;5:20-26.

-2 Kondo T, Kawai T, Akira S: Dissecting negative regulation of Toll-like receptor signaling. Trends Immunol 2012;33:449-458.

-3 Liu W, Wu H, Chen L, Wen Y, Kong X, Gao WQ: Park7 interacts with p47(phox) to direct NADPH oxidasedependent ROS production and protect against sepsis. Cell Res 2015;25:691-706.

4 Kong X, Thimmulappa R, Kombairaju P, Biswal S: NADPH oxidase-dependent reactive oxygen species mediate amplified TLR4 signaling and sepsis-induced mortality in Nrf2-deficient mice. J Immunol 2010;185:569-577.

5 Quoilin C, Mouithys-Mickalad A, Lecart S, Fontaine-Aupart MP, Hoebeke M: Evidence of oxidative stress and mitochondrial respiratory chain dysfunction in an in vitro model of sepsis-induced kidney injury. Biochim Biophys Acta 2014;1837:1790-1800.

6 Zollbrecht C, Persson AEG, Lundberg JO, Weitzberg E, Carlstrom M: Nitrite-mediated reduction of macrophage NADPH oxidase activity is dependent on xanthine oxidoreductase-derived nitric oxide but independent of S-nitrosation. Redox Biology 2016;10:119-127.

-7 Pan LL, Liu XH, Shen YQ, Wang NZ, Xu J, Wu D, Xiong QH, Deng HY, Huang GY, Zhu YZ: Inhibition of NADPH oxidase 4-related signaling by sodium hydrosulfide attenuates myocardial fibrotic response. Int J Cardiol 2013;168:3770-3778.

-8 Pan LL, Liu XH, Gong QH, Yang HB, Zhu YZ: Role of cystathionine gamma-lyase/hydrogen sulfide pathway in cardiovascular disease: a novel therapeutic strategy? Antioxid Redox Signal 2012;17:106-118.

-9 Wei X, Zhang B, Zhang Y, Li H, Cheng L, Zhao X, Yin J, Wang G: Hydrogen Sulfide Inhalation Improves Neurological Outcome via NF-kappaB-Mediated Inflammatory Pathway in a Rat Model of Cardiac Arrest and Resuscitation. Cell Physiol Biochem 2015;36:1527-1538.

10 Zhao W, Zhang J, Lu Y, Wang R: The vasorelaxant effect of H(2)S as a novel endogenous gaseous K(ATP) channel opener. EMBO J 2001;20:6008-6016.

11 Huang Z, Zhuang X, Xie C, Hu X, Dong X, Guo Y, Li S, Liao X: Exogenous Hydrogen Sulfide Attenuates High Glucose-Induced Cardiotoxicity by Inhibiting NLRP3 Inflammasome Activation by Suppressing TLR4/NFkappaB Pathway in H9c2 Cells. Cell Physiol Biochem 2016;40:1578-1590. 


\section{Cellular Physiology Cell Physiol Biochem 2018;47:458-474

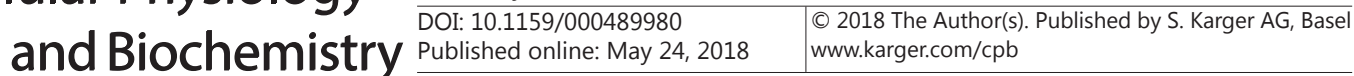 \\ Wang et al.: $\mathrm{H}_{2} \mathrm{~S}$ Modulates Inflammation Through Nox4 Activation}

12 Zheng D, Dong S, Li T, Yang F, Yu X, Wu J, Zhong X, Zhao Y, Wang L, Xu C, Lu F, Zhang W: Exogenous Hydrogen Sulfide Attenuates Cardiac Fibrosis Through Reactive Oxygen Species Signal Pathways in Experimental Diabetes Mellitus Models. Cell Physiol Biochem 2015;36:917-929.

$>13$ Yu Q, Lu Z, Tao L, Yang L, Guo Y, Yang Y, Sun X, Ding Q: ROS-Dependent Neuroprotective Effects of NaHS in Ischemia Brain Injury Involves the PARP/AIF Pathway. Cell Physiol Biochem 2015;36:1539-1551.

14 Collin M, Anuar FBM, Murch O, Bhatia M, Moore PK, Thiemermann C: Inhibition of endogenous hydrogen sulfide formation reduces the organ injury caused by endotoxemia. Br J Pharmacol 2005;146:498-505.

15 Chen SW, Bu DF, Ma YY, Zhu J, Sun L, Zuo S, Ma J, Li TY, Chen ZY, Zheng YW, Wang X, Pan YS, Wang PY, Liu YC: GYY4137 ameliorates intestinal barrier injury in a mouse model of endotoxemia. Biochemical Pharmacology 2016;118:59-67.

16 Liu XH, Zhang QY, Pan LL, Liu SY, Xu P, Luo XL, Zou SL, Xin H, Qu LF, Zhu YZ: NADPH oxidase 4 contributes to connective tissue growth factor expression through Smad3-dependent signaling pathway. Free Radic Biol Med 2016;94:174-184.

17 Miao L, Shen X, Whiteman M, Xin H, Shen Y, Xin X, Moore PK, Zhu YZ: Hydrogen Sulfide Mitigates Myocardial Infarction via Promotion of Mitochondrial Biogenesis-Dependent M2 Polarization of Macrophages. Antioxid Redox Signal 2016;25:268-281.

18 Hu Q, Wu D, Ma F, Yang S, Tan B, Xin H, Gu X, Chen X, Chen S, Mao Y, Zhu YZ: Novel Angiogenic Activity and Molecular Mechanisms of ZYZ-803, a Slow-Releasing Hydrogen Sulfide-Nitric Oxide Hybrid Molecule. Antioxid Redox Signal 2016;25:498-514.

19 Yang T, Peleli M, Zollbrecht C, Giulietti A, Terrando N, Lundberg JO, Weitzberg E, Carlstrom M: Inorganic nitrite attenuates NADPH oxidase-derived superoxide generation in activated macrophages via a nitric oxide-dependent mechanism. Free Radic Biol Med 2015;83:159-166.

-20 Pan LL, Liu XH, Shen YQ Wang NZ, Xu J, Wu D, Xiong QH, Deng HY, Huang GY, Zhu YZ: Inhibition of NADPH oxidase 4-related signaling by sodium hydrosulfide attenuates myocardial fibrotic response. Int J Cardiol 2013;168:3770-3778.

21 Liu XH, Pan LL, Deng HY, Xiong QH, Wu D, Huang GY, Gong QH, Zhu YZ: Leonurine (SCM-198) attenuates myocardial fibrotic response via inhibition of NADPH oxidase 4. Free Radic Biol Med 2013;54:93-104.

$\checkmark 22$ Wei J, Wei C, Wang M, Qiu X, Li Y, Yuan Y, Jin C, Leng L, Wang J, Yang X, He F: The GTPase-activating protein GIT2 protects against colitis by negatively regulating Toll-like receptor signaling. Proc Natl Acad Sci U S A 2014;111:8883-8888.

23 Oh GS, Pae HO, Lee BS, Kim BN, Kim JM, Kim HR, Jeon SB, Jeon WK, Chae HJ, Chung HT: Hydrogen sulfide inhibits nitric oxide production and nuclear factor-kappaB via heme oxygenase-1 expression in RAW264.7 macrophages stimulated with lipopolysaccharide. Free Radic Biol Med 2006;41:106-119.

24 Xu Y, Du HP, Li J, Xu R, Wang YL, You SJ, Liu H, Wang F, Cao YJ, Liu CF, Hu LF: Statins upregulate cystathionine gamma-lyase transcription and H2S generation via activating Akt signaling in macrophage. Pharmacol Res 2014;87:18-25.

25 Ferlito M, Wang Q, Fulton WB, Colombani PM, Marchionni L, Fox-Talbot K, Paolocci N, Steenbergen C: Hydrogen sulfide [corrected] increases survival during sepsis: protective effect of CHOP inhibition. J Immunol 2014;192:1806-1814.

-26 Yang R, Qu C, Zhou Y, Konkel JE, Shi S, Liu Y, Chen C, Liu S, Liu D, Chen Y, Zandi E, Chen W, Zhou Y, Shi S: Hydrogen Sulfide Promotes Tet1- and Tet2-Mediated Foxp3 Demethylation to Drive Regulatory T Cell Differentiation and Maintain Immune Homeostasis. Immunity 2015;43:251-263.

27 Lin WC, Chen CW, Huang YW, Chao L, Chao J, Lin YS, Lin CF: Kallistatin protects against sepsis-related acute lung injury via inhibiting inflammation and apoptosis. Sci Rep 2015;5:12463.

28 Xu J, Chi F, Guo T, Punj V, Lee WN, French SW, Tsukamoto H: NOTCH reprograms mitochondrial metabolism for proinflammatory macrophage activation. J Clin Invest 2015;125:1579-1590.

29 Lambeth JD: NOX enzymes and the biology of reactive oxygen. Nat Rev Immunol 2004;4:181-189.

30 Zhang Z, Deng W, Kang R, Xie M, Billiar T, Wang H, Cao L, Tang D: Plumbagin Protects Mice from Lethal Sepsis by Modulating Immunometabolism Upstream of PKM2. Mol Med 2016. Doi:10.2119/ molmed.2015.00250

-31 Bedard K, Krause KH: The NOX family of ROS-generating NADPH oxidases: physiology and pathophysiology. Physiol Rev 2007;87:245-313. 


\section{Cellular Physiology Cell Physiol Biochem 2018;47:458-474 \begin{tabular}{ll|l} 
DOI: 10.1159/000489980 & & $\begin{array}{l}\text { O 2018 The Author(s). Published by S. Karger AG, Basel } \\
\text { www.karger.com/cpb }\end{array}$
\end{tabular} \\ Wang et al.: $\mathrm{H}_{2} \mathrm{~S}$ Modulates Inflammation Through Nox4 Activation}

-32 Barman SA, Chen F, Su Y, Dimitropoulou C, Wang Y, Catravas JD, Han W, Orfi L, Szantai-Kis C, Keri G, Szabadkai I, Barabutis N, Rafikova O, Rafikov R, Black SM, Jonigk D, Giannis A, Asmis R, Stepp DW, Ramesh G, Fulton DJ: NADPH oxidase 4 is expressed in pulmonary artery adventitia and contributes to hypertensive vascular remodeling. Arterioscler Thromb Vasc Biol 2014;34:1704-1715.

-33 Yeo TW, Lampah DA, Kenangalem E, Tjitra E, Price RN, Weinberg JB, Hyland K, Granger DL, Anstey NM: Impaired systemic tetrahydrobiopterin bioavailability and increased dihydrobiopterin in adult falciparum malaria: association with disease severity, impaired microvascular function and increased endothelial activation. PLoS Pathog 2015;11:e1004667.

-34 Navarro E, Buendia I, Parada E, Leon R, Jansen-Duerr P, Pircher H, Egea J, Lopez MG: Alpha7 nicotinic receptor activation protects against oxidative stress via heme-oxygenase I induction. Biochem Pharmacol 2015;97:473-481.

-35 Jha JC, Thallas-Bonke V, Banal C, Gray SP, Chow BS, Ramm G, Quaggin SE, Cooper ME, Schmidt HH, Jandeleit-Dahm KA: Podocyte-specific Nox4 deletion affords renoprotection in a mouse model of diabetic nephropathy. Diabetologia 2016;59:379-389.

-36 Zhang L, Sio SWS, Moochhala S, Bhatia M: Role of Hydrogen Sulfide in Severe Burn Injury-Induced Inflammation in Mice. Mol Med 2010;16:417-424.

37 Whiteman M, Haigh R, Tarr JM, Gooding KM, Shore AC, Winyard PG: Detection of hydrogen sulfide in plasma and knee-joint synovial fluid from rheumatoid arthritis patients: relation to clinical and laboratory measures of inflammation. Ann N Y Acad Sci 2010;1203:146-150.

38 Velmurugan GV, Huang H, Sun H, Candela J, Jaiswal MK, Beaman KD, Yamashita M, Prakriya M, White C: Depletion of H2S during obesity enhances store-operated Ca2+ entry in adipose tissue macrophages to increase cytokine production. Sci Signal 2015;8:ra128.

-39 Wang CN, Liu YJ, Duan GL, Zhao W, Li XH, Zhu XY, Ni X: CBS and CSE are critical for maintenance of mitochondrial function and glucocorticoid production in adrenal cortex. Antioxid Redox Signal 2014;21:2192-2207.

40 Ahmad A, Druzhyna N, Szabo C: Delayed Treatment with Sodium Hydrosulfide Improves Regional Blood Flow and Alleviates Cecal Ligation and Puncture (CLP) - Induced Septic Shock. Shock 2016;46:183-193.

41 Zhang Y, Lu Y, Ma L, Cao X, Xiao J, Chen J, Jiao S, Gao Y, Liu C, Duan Z, Li D, He Y, Wei B, Wang H: Activation of vascular endothelial growth factor receptor-3 in macrophages restrains TLR4-NF-kappaB signaling and protects against endotoxin shock. Immunity 2014;40:501-514.

42 Park SH, Park-Min KH, Chen J, Hu X, Ivashkiv LB: Tumor necrosis factor induces GSK3 kinase-mediated cross-tolerance to endotoxin in macrophages. Nat Immunol 2011;12:607-615.

43 Mistry RK, Murray TV, Prysyazhna O, Martin D, Burgoyne JR, Santos C, Eaton P, Shah AM, Brewer AC: Transcriptional Regulation of Cystathionine-gamma-Lyase in Endothelial Cells by NADPH Oxidase 4-Dependent Signaling. J Biol Chem 2016;291:1774-1788. 